\title{
Vitamin D in the Covid-19 era: a review with recommendations from a G.I.O.S.E.G. expert panel
}

\author{
Fabio Massimo Ulivieri $\mathbb{D}^{1} \cdot$ Giuseppe Banfi $^{2,3}$ - Valentina Camozzi ${ }^{4} \cdot$ Annamaria Colao $^{5}$ - Anna Maria Formenti ${ }^{1}$. \\ Stefano Frara ${ }^{1} \cdot$ Giovanni Lombardi $^{6,7} \cdot$ Nicola Napoli $^{8} \cdot$ Andrea Giustina $^{1}$
}

Received: 3 March 2021 / Accepted: 3 May 2021 / Published online: 17 May 2021

(c) The Author(s), under exclusive licence to Springer Science+Business Media, LLC, part of Springer Nature 2021

\begin{abstract}
Vitamin D (VITD) is a key hormone for bone health and has relevant extra-skeletal effects that might play a role in the prevention and treatment of COronaVIrus Disease 19 (COVID-19). Literature regarding this scenario is voluminous but controversial. Glucocorticoid Induced Osteoporosis Skeletal Endocrinology Group (G.I.O.S.E.G) has been present in the scientific debate about the use of VITD and has regularly interfaced national regulatory agencies to ensure appropriateness of its employment. Given the current pandemic and the questions on COVID-19 and VITD, G.I.O.S.E.G. appointed an expert panel to advise how to consider this issue best. The results of these deliberations are reported in the current recommendation paper.
\end{abstract}

Keywords Vitamin D $\cdot$ VITD $\cdot$ Pandemic $\cdot$ COVID-19 $\cdot$ Sars-Cov-2 $\cdot$ G.I.O.S.E.G.

\section{Introduction}

Vitamin D (VITD) is a key hormone for bone health and has immunomodulatory actions of relevance in the context of the COronaVIrus Disease 19 (COVID-19) pandemic [1]. Unfortunately, hypovitaminosis D is widespread, due in part to reduction in sun exposure without compensatory measures, such as food fortification with VITD or VITD supplementation. Elderly subjects who are at greatest risk for

The authors declare that no funds, grants, or other support were received for this article.

All the authors equally contribute to this article and consent for publication.

Fabio Massimo Ulivieri

ulivieri@gmail.com

1 Institute of Endocrine and Metabolic Sciences (IEMS), San Raffaele Vita-Salute University, IRCCS San Raffaele Hospital, Via Olgettina 20, Milan, Italy

2 IRCCS Istituto Ortopedico Galeazzi, Via Riccardo Galeazzi, 4, Milan, Italy

3 San Raffaele Vita-Salute University, Via Olgettina 20, Milan, Italy

4 Endocrinology Unit, Department of Internal Medicine (DIMED), Padua Hospital-University, Via Nicolò Giustiniani, 2, Padua, Italy adverse outcomes of COVID-19, more frequently present low levels of VITD [2]. Working at cross purposes, regulatory authorities in countries such as Italy have limited reimbursement of VITD for budgetary reasons, thus limiting access to this important nutrient [3]. The GlucocorticoidInduced Osteoporosis and Skeletal Endocrinology Group (G.I.O.S.E.G.) has co-sponsored International Consensus Conferences on laboratory, clinical and therapeutic aspects of VITD [2, 4, 5]. It has also sponsored a document on the role of VITD in clinical medicine that addresses issues that include socio-economic ones [6] Our view, antecedent to the pandemic period, is that the only effective strategy to ensure adequate intake of VITD is not limiting access to it. To this point, a relevant emphasis on prevention of hypovitaminosis D through systematic food fortification and/or supplementation is germane [6,7]. The European Union (E.U.)

5 Department of Clinical Medicine and Surgery, University Federico II of Naples, Corso Umberto I, 40, Naples, Italy

6 Laboratory of Experimental Biochemistry \& Molecular Biology, IRCCS Istituto Ortopedico Galeazzi, Via Riccardo Galeazzi 4, Milan, Italy

7 Department of Athletics Strength and Conditioning, Poznań University of Physical Education, Królowej Jadwigi 27/39, 61-871 Poznań, Poland

8 Endocrinology and Metabolic Diseases, Campus Bio Medico University of Rome, Via Álvaro del Portillo, 200, Rome, Italy 
also plays a relevant role in this regard, tackling differences between its countries.

Vitamin D deficiency has a potential negative impact on the incidence and prognosis of COVID-19. which it is also characterised by high prevalence of vertebral fractures [8]. However, practical guidelines and recommendations on how to handle this issue are lacking. Instead, only erudite reviews and expert opinions on vitamin D in COVID-19 are available in the literature [9]. This position paper has been produced by an expert panel appointed by G.I.O.S.E.G. in order to address the clinically relevant issue of VITD supplementation in the COVID-19 scenario.

The literature search refers to the papers, with particular attention to meta-analysis and systematic review, published in 2020 and 2021 by Medline, PubMed, Scopus. with the following keywords: 'COVID-19', 'Vitamin D', 'Elderly'.

\section{Extra-skeletal effects of vitamin D}

VITD exerts multiple pleiotropic effects beyond its crucial role in calcium-phosphate metabolism and bone homoeostasis. Its deficiency is associated with an increased risk for cancer, cardiovascular diseases, diabetes, obesity, and immune-related diseases [1]. VITD production starts in the skin and ends in the kidney, with the conversion to the active form 1,25 dihydroxyvitamin $\mathrm{D}\left[1,25(\mathrm{OH})_{2} \mathrm{D}\right]$ that binds with the vitamin $\mathrm{D}$ receptor (VDR), a member of the nuclear receptor family of transcription factors. VITD/VDR constitutes a complex that acts as a transcription factor to induce the genes that enable intestinal calcium and phosphate transport, renal reabsorption of calcium, and calcium and phosphate flow in the skeleton [10]. VDR also plays an essential role in the pleiotropic effects of VITD. In fact, VDR is detected in nearly all the cells in the body and 25 hydroxylases are widely expressed. Indeed, all cells may be targeted for $1,25(\mathrm{OH})_{2} \mathrm{D}$ at least at some stage of their differentiation [11].

Furthermore, many of these cells make their own 1,25 $(\mathrm{OH})_{2} \mathrm{D}$ and are not dependent on this metabolite's renal production [11]. VDR is an intranuclear receptor capable of binding specific DNA sequences (VDR response elements), regulating the transcription of over 60 genes belonging to different cell lines. VITD, therefore, regulates mineral metabolism and influences the processes of cell proliferation, differentiation and adhesion, cardiovascular physiology, immune functions, and carcinogenesis.

The cardiovascular system appears to be a target for VITD. VDR is present in vascular smooth muscle cells and cardiomyocytes. Human observational data also indicate that insufficient VITD levels are associated with several cardiovascular risk factors, an increased risk of myocardial infarction and cardiovascular disease mortality. It is better established in the association between VITD deficiency and obesity. Although VITD actions on adipose metabolism are controversial, there are several pieces of evidence that it regulates lipid synthesis, lipolysis and improves insulin signalling pathways. These results suggest that VITD may ameliorate adipose tissue dysfunctions, linking low VITD status to metabolic disease in obesity [12]. On the other hand, obesity per se seems to involve low circulating levels of VITD, due to low sun exposure, low physical activity, low intake of foods rich in VITD and volumetric dilution and sequestration in the adipose tissue. This connection is essential when considering obesity-related diseases. Low VITD levels and severe obesity are significantly associated with some cardio-metabolic risk factors, including high body mass index, waist circumference, blood pressure, impaired lipid and glycaemic profile, and insulin resistance, as they seem associated with worse cardiovascular outcomes and higher cancer incidence and mortality [13]. Most of the immune cells, such as macrophages, T and B lymphocytes, neutrophils and dendritic cells express VDR. This suggests that VITD may carry out pleiotropic actions on the innate and acquired immune system. VDR and VITD metabolic enzymes are present in virtually all immune system cells' innate and adaptive arms [14, 15]. Numerous clinical studies have revealed associations between VITD deficiency and increased risk of infections, particularly in the upper respiratory tract $[4,16]$. In innate immunity, VITD has several antimicrobial activities, ranging from interference in iron metabolism to generation of reactive oxygen species, enhancement of killing functions in neutrophils, stimulation of phagocytic and auto-phagocytic activity in macrophages, induction of antimicrobial antiviral compounds cathelicidins and $\beta$-defensin $2[17,18]$.

For all these reasons, there is a growing interest in the possible correlation between low levels of VITD and infection from the SARS-CoV-2 and the supplementation with VITD for COVID-19 prevention and management.

\section{Vitamin D in the elderly}

VITD deficiency is a widespread medical issue among the elderly. Its prevalence is higher in older adults and highest in community-dwelling older people [19]. This condition tends to increase in the range of 'oldest old' adults ( $>80$ years): data from the KORA-Age study [20] show that the proportion of older adults with serum $25(\mathrm{OH}) \mathrm{D}$ concentrations $<50 \mathrm{nmol} / 1$ increases from $44 \%$ in the $65-74$ years old to $74 \%$ in the 85-93 years old. Seniors had two times higher odds of having low plasma levels of 25(OH)D than their 65-74- year-old counterparts [20]. Several reasons are currently recognised for the higher tendency to develop VITD deficiency in the elderly. First of all, they have less daily sun exposure and a reduced cutaneous synthesis, thus leading to decreased dermal productions of 
cholecalciferol [21]. Secondly, renal function, declining with age, leads to a decrease in the activity of the renal enzyme 1alpha-hydroxylase that converts $25(\mathrm{OH}) \mathrm{D}$ into calcitriol. Calcitriol levels have been shown to be inversely linked to the serum creatinine levels and to the glomerular filtration rate [22]. Other factors involved are the reduced VDR expression in skeletal muscles and the decline in the intestine's sensitivity to calcitriol, and the consequent reduction in calcium absorption [21]. Low levels of VITD have been implicated in various frequent diseases in the geriatric population, including fractures, functional limitations, cancer, cardiovascular diseases and depression. Additionally, mortality has been associated with low VITD [21]. Serum levels of VITD are independently related to the loss of muscle mass and to muscle strength decline [23], suggesting that older people with VITD deficiency are overly exposed to develop sarcopenia. Besides that, observational studies suggest that older individuals with VITD deficiency have a significant risk of other critical geriatric outcomes, such as frailty and falls [24, 25]. Although the 'oldest-old' are most at risk of VITD deficiency, sarcopenia, and functional decline, only a few studies have focused explicitly on this population [26].

\section{COVID-19}

COVID-19 is an infectious disease caused by a newly discovered coronavirus $[27,28]$ that started in the last months of the year 2019 and was declared to be a pandemic disease by WHO in March 2020 (WHO Official Updates Coronavisrus disease 2020.). COVID-19 is a global disease. In Italy, there have been 4832.2 per 100,000 confirmed cases with 161,59 per 100,000 deaths, according to data provided on 2 March 2021 [27].

The European Centre for Disease Prevention and Control [29] (ECDC) claims that high-risk groups for COVID-19 are people over 60 years. A meta-analysis reported that patients aged $<65 \mathrm{yrs}$ had 30 to 100 fold lower risk of death in COVID-19 than those $>65$ yrs in Europe and Canada, 16 to 52 fold lower risk in the U.S.A., and less than tenfold in India and Mexico [30], confirming that older persons need to be focused for protective measures to reduce death risk in COVID-19.

Regarding gender, males present a major risk for mortality than women (RR 1.86 95\%CI 1.67-2.07) as reported in a recent meta-analysis focused on age and sex association with COVID-19 mortality [31].

Patients living in long-term care facilities and people with underlying health conditions, such as hypertension, diabetes, cardiovascular diseases, chronic respiratory diseases, immune-compromised status, cancer, smoking and obesity, present a high risk of severe/fatal COVID-19. A few recent meta-analyses have confirmed that these underlying diseases and conditions are frequently present in hospitalised patients with COVID-19 and in its dead cases [30-46].

The most prevalent chronic comorbidities associated with COVID-19 serious event/mortality reported in literature were up to $42 \%$ for obesity [32]; $46 \%$ for hypertension $[33,37] ; 13 \%$ for cardiovascular diseases; $8 \%$ for respiratory diseases; $4 \%$ for malignancy; $3 \%$ for kidney diseases; $2 \%$ for liver diseases [32]. Diabetes was reported up to $25.2 \%$ [37]. Recently, morphometric vertebral fractures have been reported to be highly prevalent in COVID-19 patients, and in that context their severity resulted in increased mortality risk [8].

Regarding the prediction, the OR/RR of the comorbidities in patients with severe/fatal COVID-19 compared with non-severe/fatal ranged from 1.94 to 6.66 for chronic respiratory diseases [31, 40, 44, 47]; from 1.82 to 3.17 for hypertension; [31, 32, 38, 40] from 4.58 to 3.05 for cardiovascular diseases [31, 32, 37, 40, 44]; from 5.3 to 3.02 for kidney diseases; [31, 37, 38, 40, 44] from 2.74 to 4.78 for cerebrovascular diseases [31, 32]; from 1.47 (1.01.2.149) to 2.73 for malignancy [31, 32, 37, 38, 40]; from 1.48 to 3.07 for diabetes [31, 38, 40, 48]; of 1.72 for obesity [32]. Nonunivocal results are reported for liver disease and COVID19 [49, 50]. Furthermore, 37\% of COVID-19 patients had at least one comorbidities, $28 \%$ two comorbidities and $19 \%$ three or more [39].

ECDC estimates that up to $30 \%$ of the E.U. and European Economic Area population and that of the United Kingdom is either over 60 years old or has one of the underlying conditions associated with the COVID-19 risk.

Although most people with an elevated risk of severe COVID-19 disease live independently or with family, some reside in long-term care facilities, where infection tends to spread quickly.

Residents in care homes are a particularly vulnerable population group. In several European countries, these deaths represent 30-60\% of all COVID-19 related deaths [29]. Currently, there are no specific drug therapies, and vaccine prophylaxis started only a few months ago. For these reasons, all measures preventing SARS-COV-2 infection are required to reduce hospitalisation risk and every measure of pharmacological therapy is essential to reduce mortality. As previously reported, VITD deficiency is a widespread condition at all ages, especially in the elderly and in those with comorbidities, such as diabetes mellitus and obesity, where severe/fatal COVID-19 is a more frequent event [51].

\section{COVID-19 and vitamin D}

A low VITD status associates with hypocalcaemia, a condition frequently described in the course of other epidemics 
(e.g., Ebola in 2016 and SARS in 2003) [52], as well as in up to $80 \%$ of hospitalised SARS-CoV-2 infected Italian patients and other cohorts [53]. It was observed that the lower the calcium, the poorer the prognosis [54]. Free intracellular calcium is needed for viral replication and the NOD-, LRR- and pyrin domain-containing protein 3 (NLRP3) inflammasome complex-related SARS response [55]. Further, in coronaviruses infections, included SARS$\mathrm{CoV}-2$, calcium mediates the viral envelope's fusion with the host cell membrane throughout the viral spike (S) fusion protein subunit $\mathrm{S} 1 / \mathrm{S} 2$ and the cell endocytic machinery or the transmembrane domain of angiotensin-converting enzyme (ACE)2, respectively [56]. The consequent downregulation of ACE2 impairs the conversion of angiotensin II (Ang-II) into angiotensin 1-7 (Ang [1-7].) and, in turn, triggers an abnormal inflammatory response ('cytokine storm') and tissue damage that cause the acute respiratory distress syndromes (ARDS) [57]. VITD has a potential protective role against ARDS, since it inhibits renin expression and the ACE/Ang-II/AT1R axis and stimulates the ACE2/Ang-(1-7)/MasG (G protein-coupled Mas receptor) [58]. VITD may have a direct role in mitigating the cytokine storm by introducing anti-inflammatory mediators (i.e., IL-10, IL-4, transforming growth factor $\beta$ ) and by inducing immune-tolerance, as described above [59].

\section{Evidence for vitamin D involvement in SARS-CoV-2 infection}

Besides the multiple observations of an indirect link, a cause-effect association between VITD status, SARS-CoV2 infection risk and COVID-19 severity has not been definitively established. Such a scenario is plausible, but comorbidities and age may play a more significant role than VITD in COVID-19 fatal events. However, on a long-term basis, a low VITD status may be itself a determinant of the subject's comorbidity status and, hence, more or less directly of COVID-19 severity [60]. Sunlight exposure is one (but not the primary) factor involved in endogenous VITD biosynthesis. The few published studies, mainly referred to the first pandemic wave, describe a fair but significant association between diseases' outbreak and latitude [61]. From analysis, over 108 days, in 152 countries, Moozhipurath et al. found that a permanent unit increase in the ultraviolet index is associated with a $1.2 \%$ decline in daily growth rates of cumulative COVID-19 deaths and a $1.0 \%$ decline in the case-fatality daily growth rate [62]. Similarly, the monthly average per cent positive of four common coronaviruses (CoVHKU1, CoVNL63, CoVOC43 and CoV229E) and SARS-CoV-2 are negatively correlated with the sunlight ultraviolet radiation dose in the U.S. [63]. Prototypically, Italy, one of the European countries with the highest prevalence of hypovitaminosis D, has experienced a high prevalence of SARS-CoV-2 infection and COVID-19, especially in the Northern regions [64]. In a large retrospective study, US cohort (over 190,000 subjects, from the 50 states) from March to June 2020, the COVID19 infection correlated with the VITD status was tested in the previous 12 months. Higher incidence rate of SARSCoV-2 resulted positivity correlated with VITD deficiency compared to subjects with adequate VITD status [25(OH)D values $<20 \mathrm{ng} / \mathrm{mL} ; 12.5 \%$, (95\% C.I. $12.2-12.8 \%) ; 25(\mathrm{OH})$ $\mathrm{D}$ values $=30-34 \mathrm{ng} / \mathrm{mL}, 8.1 \%$, (95\% C.I. $7.8-8.4 \%)$ and $25(\mathrm{OH})_{2} \geq 55 \mathrm{ng} / \mathrm{mL}, 5.9 \%$ (95\% C.I. $5.5-6.4 \%$ ). Such a relationship persists after multivariate analysis across latitudes, races/ethnicities, gender and age ranges [65].

\section{Vitamin D status and SARS-CoV-2 infection risk and outcomes}

Since the pandemic broke out, many studies have been published bout a link between VITD and COVID-19. They were mostly observational cross-sectional, retrospective cohort and, to a lesser extent, prospective cohort or randomised controlled trial.

Nevertheless, they include series that vary in a number of subjects, VITD levels and outcomes. For this reason, it seemed more appropriate to refer to the information obtained from meta-analyses and systematic reviews, to understand the relation between VITD and COVID-19, in terms of risk of infection, prognosis (request for intensive care and mortality) and usefulness of pharmacological intervention. The cited literature declares to have referred to the year 2020 and to have been carried out considering the major databases such as Medline, PubMEd, Google Scholar, EMBASE, Cochrane Trial Register, WHO International Clinical Trial Registry, and Nexis media database. The selection of publications was planned according to the PRISMA guidelines and the quality assessment guaranteed by the GRADE system or Newcaste-Ottawa scale.

\section{Infection risk}

VITD deficiency or insufficiency, defined as $25(\mathrm{OH}) \mathrm{D}$ below $20 \mathrm{ng} / \mathrm{ml}(50 \mathrm{nmol} / \mathrm{L})$ or $25(\mathrm{OH}) \mathrm{D}$ between $21-29 \mathrm{ng} / \mathrm{ml}$ $(52.2-72.5 \mathrm{nmol} / \mathrm{L})$ respectively, was associated with an increased risk of COVID-19 infection (OR $=1.43,95 \%$ CI 1.00-2.05). In COVID-19 positive or negative subjects, the mean value of VITD was lower in the positive ones (SMD = $-0.37,95 \% \mathrm{CI}=0.52$ to $-0.21, \mathrm{I}^{2}=89.6 \%$ ). The sources included the over 50 years old within a wide range of ages, from Asia, Europe and the United States [66]. A very recently published paper, considering both the so-called first and the second pandemic waves (1st March-30th April 2020 and 1st October-30th November 2020, respectively), based on 40996 25-(OH)D determinations, did not find any direct relationship 
between VITD status, putative UV dose, and SARS-CoV-2 infection risk [67].

\section{Prognosis}

VITD deficiency has been found to correlate with the severity of COVID-19 infections, especially in the elderly. In this category, known to be affected by multiple chronic diseases that increase the severity of the COVID-19 infection, it was found that subjects with severe disease had $65 \%$ $(\mathrm{OR}=1.65 ; 95 \% \mathrm{CI}=1.30-2.09 ; \mathrm{I} 2=35.7 \%)$ more VITD deficiency compared to the mildly affected ones. VITD insufficiency favours hospitalisation $(\mathrm{OR}=1.81,95 \% \mathrm{CI}=$ $1.41-2.21)$ and mortality $(\mathrm{OR}=1.82,95 \% \mathrm{CI}=1.06-2.58)$ [68]. Selecting subjects COVID-19 positive for severity and prognosis, an average VITD value of $21.9 \mathrm{nmol} / \mathrm{L}$ (15.36-28.45), with a significant heterogeneity $\left(I^{2}=99.1 \%\right.$, $p<0.001)$, lower values were observed in Asian affected patients. The poorer the prognosis, the worse the VITD status (mean difference adjusted $-0.58(95 \% \mathrm{CI}=0.83$ to $-0.34, p<0.001)$ : this discrepancy appears magnified in patients requiring intensive care unit (ICU) $(\mathrm{SMD}=-0.50$, $95 \% \mathrm{CI}=-1.32$ to $-0.36, p=0.001$ ) so that VIT D deficiency seems almost to be an independent cause of disease severity [69]. On survival analysis, patients admitted to the ICU with the worst VITD deficiency had a higher risk of mortality (50\%) after ten days of hospitalisation (OR 5.681, 95\% CI 1.114-25.974; $p=0.037$ ) [70].

\section{The usefulness of pharmacological intervention}

The role of VITD administration in the course of the infection is a more challenging goal to achieve and some preliminary data seem to demonstrate its benefit.

In a retrospective study, cholecalciferol booster therapy was associated with a reduced risk of COVID-19 mortality, following adjustment for potential confounders (OR: 0.13, 95\% CI: $0.05-0.35)$, regardless of baseline serum $25-(\mathrm{OH})$ D levels [71].

The administration of a high dose of calcifediol reduces the need for ICU in the hospitalised patient: the multivariate risk estimate for ICU patients who receive or not calcifediol was 0.03 (95\% CI 0.003-0.25) [70].

\section{G.I.O.S.E.G. panel recommendations}

The cited studies suggested that supplementing VITD in intensive care COVID-19 patients could improve outcomes and some specific data on the treatment of severe patients with VITD are available. Currently, however, reliable interventional data with VITD supplementation in hospitalised COVID-19 patients are not available.
We think that in the COVID-19 scenario, VITD has a primary role in prevention and it is wise to grant an adequate vitamin $\mathrm{D}$ level to the population at high risk of both hypovitaminosis D and COVID-19. VITD extra-skeletal effects may be beneficial in exerting a protective role in tackling COVID-19, mainly by the immunomodulatory action of this steroid hormone.

It is worth mentioning that older males, particularly affected by the consequences of SARS-CoV-2 infection, are traditionally less monitored than older women [72]. This is due to the well-known reverse gender bias, which principally attributes osteoporosis and bone metabolic disorders to the female gender; and thus it is not just by chance that COVID-19 hospitalised males present lower VITD levels [73] and worse prognosis in comparison to females [72].

Therefore, we recommend that all subjects with known hypovitaminosis D or under treatments that recommend VITD supplementations (anti-osteoporotic drugs, glucocorticoids and antiepileptic drugs) should continue, resume or start VITD supplementation [74, 75].

We also recommend that elderly begin, if not already started, VITD supplementation independently of their baseline VITD status assessment, considering the high prevalence of VITD deficiency in this age group [2, 4, 76]. Treatment should be initiated independently from the subjects' status in terms of self-sufficiency or living in a community.

We recommend that subjects of both sexes with comorbidities predisposing to both hypovitaminosis D and severe COVID-19 such as diabetes or obesity [76] are carefully evaluated for their risk profile of hypovitaminosis $\mathrm{D}$ based on clinical judgement submitted to $25 \mathrm{OH}$ VITD assay. Optimal VITD levels to achieve in the COVID-19 scenario are still controversial, but for lower than $20 \mathrm{ng} / \mathrm{ml}$ VITD levels, VITD supplementation is mandatory.

We suggest to use forms and doses of VITD as indicated for VITD supplementation in hypovitaminosis D by the national regulatory drug agencies and by scientific bodies that deal with metabolic bone diseases [77], in order to ensure a rapid achievement of appropriate VITD level. In fact, we believe that in the current situation it is important to reach rapidly the appropriate levels to ensure that COVID19 hospitalised patients may benefit from the VITD effects. It should be noted, and it is related to the above recommendations, that obese subjects may require higher doses of pre-active VITD or active VITD to be adequately supplemented [78].

Finally, no evidence is published on the immune response's potential improvement with VITD to COVID-19 vaccination [79]. However, the unprecedented worldwide ant COVID-19 vaccination effort of the whole elderly population offers, in our view, a unique occasion to bring to medical attention the widespread hypovitaminosis D issue. 
This approach may allow us to tackle the double pandemic question, COVID-19 and VITD deficiency [80-82], at once by co-administering COVID-19 vaccine and VITD in the forms and doses recommended by the specific current guidelines.

\section{Conclusions}

Reaching an adequate VITD status in the population is a good clinical practice to prevent extra-skeletal adverse effects of low VITD levels, which may interfere negatively with the course of COVID-19.

In a long term-scenario of COVID-19 era, public Health Authorities should prospect at widespread food fortification projects with VITD, to preserve the positive extra-skeletal effects of VITD.

In the short-term scenario of COVID-19 era we think that public Health Authorities and Scientific Societies should team up to identify subjects with increased risk for complications or death from COVID-19 in whom VITD supplementation is mandatory, due to its alleged or proved deficiency.

In the COVID-19 pandemic conditions, we believe that these recommendations should become shared measures to be added to vaccination plans. On the other hand, we think there is not enough evidence to routinely add VITD to the treatment protocols in COVID-19 hospitalised patients.

\section{Compliance with ethical standards}

Conflict of interest The authors declare no competing interests.

Publisher's note Springer Nature remains neutral with regard to jurisdictional claims in published maps and institutional affiliations.

\section{References}

1. R. Bouillon, C. Marcocci, G. Carmeliet, D. Bikle, J.H. White, B. Dawson-Hughes, P. Lips, C.F. Munns, M. Lazaretti-Castro, A. Giustina, J. Bilezikian, Endocr. Rev. 40, 1109 (2019)

2. A. Giustina, R.A. Adler, N. Binkley, J. Bollerslev, R. Bouillon, B. Dawson-Hughes, P.R. Ebeling, D. Feldman, A.M. Formenti, M. Lazaretti-Castro, C. Marcocci, R. Rizzoli, C.T. Sempos, and J.P. Bilezikian, in Rev. Endocr. Metab. Disord. (Springer, 2020), pp. 89-116

3. D. N.1533/2019, Gazz. Uff. Della Repubb. Ital. https://www.aifa. gov.it/documents/20142/1030827/Determina_n.1533_2019_Nota 96.pdf/82e17738-8ea7-c77e-3d1c-6403385703cc (2019)

4. A. Giustina, R.A. Adler, N. Binkley, R. Bouillon, P.R. Ebeling, M. Lazaretti-Castro, C. Marcocci, R. Rizzoli, C.T. Sempos, J.P. Bilezikian, J. Clin. Endocrinol. Metab. 104, 234 (2018)

5. A. Giustina, R. Bouillon, N. Binkley, C. Sempos, R.A. Adler, J. Bollerslev, B. Dawson-Hughes, P.R. Ebeling, D. Feldman, A. Heijboer, G. Jones, C.S. Kovacs, M. Lazaretti-Castro, P. Lips, C. Marcocci, S. Minisola, N. Napoli, R. Rizzoli, R. Scragg, J.H. White, A.M. Formenti, and J.P. Bilezikian, JBMR Plus 4, (2020)
6. G.I.O.S.E.G. Glucocorticoid Induced Osteoporosis Skeletal Endocrinology Group, Vitamin D: An essential hormone for skeletal health - 2020 Update. Available at: https://www.gioseg. org/en/comunicato-vitamina-d (2020)

7. T. Hirvonen, H. Sinkko, L. Valsta, M.L. Hannila, P. Pietinen, Eur. J. Nutr. 46, 264 (2007)

8. L. di Filippo, A.M. Formenti, M. Doga, E. Pedone, P. RovereQuerini, A. Giustina, J. Clin. Endocrinol. Metab. 106, e602 (2021)

9. J.P. Bilezikian, D. Bikle, M. Hewison, M. Lazaretti-Castro, A.M. Formenti, A. Gupta, M.V. Madhavan, N. Nair, V. Babalyan, N. Hutchings, N. Napoli, D. Accili, N. Binkley, D.W. Landry, A. Giustina, Eur. J. Endocrinol. 183, R133 (2020)

10. D.D. Bikle, Ann. N. Y. Acad. Sci. 1376, 29 (2016)

11. M.J. Damasiewicz, P.G. Kerr, K.R. Polkinghorne, Clin. Nephrol. 84, 65 (2015)

12. H. Nimitphong, E. Park, M.J. Lee, Nutr. Res. Pract. 14, 553 (2020)

13. L. Barrea, E. Frias-Toral, G. Pugliese, E. Garcia-Velasquez, M. De Los Angeles Carignano, S. Savastano, A. Colao, and G. Muscogiuri, Minerva Endocrinol. (2020)

14. R.F. Chun, P.T. Liu, R.L. Modlin, J.S. Adams, and M. Hewison, Front. Physiol. (2014)

15. A.S. Vanherwegen, C. Gysemans, C. Mathieu, Endocrinol. Metab. Clin. North Am. 46, 1061 (2017)

16. J.H. White, Infect. Immun. 76, 3837 (2008)

17. M.E. Gough, E.A. Graviss, E.E. May, Innate Immun. 23, 506 (2017)

18. K. Subramanian, P. Bergman, B. Henriques-Normark, J. Innate Immun. 9, 375 (2017)

19. J.-C. Souberbielle, C. Cormier, C. Kindermans, P. Gao, T. Cantor, F. Forette, E.E. Baulieu, J. Clin. Endocrinol. Metab. 86, 3086 (2001)

20. R. Conzade, W. Koenig, M. Heier, A. Schneider, E. Grill, A. Peters, and B. Thorand, Nutrients 9, (2017)

21. L.E. Bode, M. McClester Brown, E.M. Hawes, J. Am. Med. Dir. Assoc. 21, 164 (2020)

22. K.S. Tsai, H. Heath, R. Kumar, B.L. Riggs, J. Clin. Invest. 73, 1668 (1984)

23. D.K. Houston, J.A. Tooze, D.B. Hausman, M.A. Johnson, B.J. Nicklas, M.E. Miller, R.H. Neiberg, A.P. Marsh, A.B. Newman, S.N. Blair, S.B. Kritchevsky, J. Gerontol.-Ser. A Biol. Sci. Med. Sci. 66 A, 430 (2011)

24. I. Endo, D. Inoue, T. Mitsui, Y. Umaki, M. Akaike, T. Yoshizawa, S. Kato, T. Matsumoto, Endocrinology 144, 5138 (2003)

25. B. Dawson-Hughes, J. Steroid Biochem. Mol. Biol. 173, 313 (2017)

26. A. Mithal, D.A. Wahl, J.P. Bonjour, P. Burckhardt, B. DawsonHughes, J.A. Eisman, G. El-Hajj Fuleihan, R.G. Josse, P. Lips, J. Morales-Torres, Osteoporos. Int. 20, 1807 (2009)

27. WHO Health Emergency Dashboard WHO (COVID-19) Homepage: https://covid19.who.int

28. A. D'Avolio, G. Isaia, On behalf of COVID-Vitamin D Study Group, Accademia di Medicina di Torino. Vitamin D in the COVID-19 prevention andtreatment: emerging evidence. Pharma Advances 2021. https://doi.org/10.36118/pharmadvances.2021.01

29. (n.d.)

30. J.P.A. Ioannidis, C. Axfors, and D.G. Contopoulos-Ioannidis, Environ. Res. 188, (2020)

31. M. Biswas, S. Rahaman, T.K. Biswas, Z. Haque, and B. Ibrahim, Intervirology 1 (2020)

32. Y. Zhou, Q. Yang, J. Chi, B. Dong, W. Lv, L. Shen, Y. Wang, Int. J. Infect. Dis. 99, 47 (2020)

33. F. Javanmardi, A. Keshavarzi, A. Akbari, A. Emami, and N. Pirbonyeh, PLoS ONE 15, (2020)

34. A. Emami, F. Javanmardi, N. Pirbonyeh, A. Akbari, Arch. Acad. Emerg. Med. 8, e35 (2020) 
35. C.R. Jutzeler, L. Bourguignon, C.V. Weis, B. Tong, C. Wong, B. Rieck, H. Pargger, S. Tschudin-Sutter, A. Egli, K. Borgwardt, and M. Walter, Travel Med. Infect. Dis. 37, (2020)

36. S. Figliozzi, P.G. Masci, N. Ahmadi, L. Tondi, E. Koutli, A. Aimo, K. Stamatelopoulos, M.A. Dimopoulos, A.L.P. Caforio, and G. Georgiopoulos, Eur. J. Clin. Invest. 50, (2020)

37. M.M.A. Khan, M.N. Khan, M.G. Mustagir, J. Rana, M.S. Islam, M.I. Kabir, J. Glob. Health 10, 020503 (2020)

38. A. Hussain, K. Mahawar, Z. Xia, W. Yang, S. EL-Hasani, Obes. Res. Clin. Pract. 14, 295 (2020)

39. R.A. Mahumud, J.K. Kamara, A.M.N. Renzaho, Infection 48, 813 (2020)

40. N. Zádori, S. Váncsa, N. Farkas, P. Hegyi, B. Erôss, L. Szakó, N. Vörhendi, L. Frim, Z.R. Dömötör, Z. Szakács, S. Kiss, M. Földi, F. Dembrovszky, M. Imrei, Z. Molnár, Z. Péterfi, H. Alizadeh, L. Czopf, Intensive Care Med 46, 1784 (2020)

41. Z. Wang, H. Deng, C. Ou, J. Liang, Y. Wang, M. Jiang, S. Li, Medicine 99, e23327 (2020)

42. K.R. Starke, G. Petereit-Haack, M. Schubert, D. Kämpf, A. Schliebner, J. Hegewald, A. Seidler, Int. J. Environ. Res. Public Health 17, 1 (2020)

43. N. Rosenthal, Z. Cao, J. Gundrum, J. Sianis, S. Safo, JAMA Netw. Open 3, e2029058 (2020)

44. K. Nandy, A. Salunke, S.K. Pathak, A. Pandey, C. Doctor, K. Puj, M. Sharma, A. Jain, V. Warikoo, Diabetes Metab. Syndr. Clin. Res. Rev. 14, 1017 (2020)

45. B. Moazzami, S. Chaichian, A. Kasaeian, S. Djalalinia, M. Akhlaghdoust, M. Eslami, and B. Broumand, PLoS ONE 15, (2020)

46. P. Ssentongo, A.E. Ssentongo, E.S. Heilbrunn, D.M. Ba, and V. M. Chinchilli, PLoS ONE 15, (2020)

47. N. Khan, A.M. Abbas, R.M. Almukhtar, A. Khan, J. Clin. Endocrinol. Metab. 98, 2368 (2013)

48. J. Zhou, X. Ma, T. Wang, and S. Zhai, Osteoporos. Int. 27, (2016)

49. A.J. Kovalic, S.K. Satapathy, P.J. Thuluvath, Hepatol. Int. 14, 612 (2020)

50. Z. hong Wu and D. Yang, Eur. J. Med. Res. 25, (2020)

51. N. Hutchings, V. Babalyan, S. Baghdasaryan, M. Qefoyan, N. Sargsyants, E. Aghajanova, A. Martirosyan, R. Harutyunyan, O. Lesnyak, A.M. Formenti, A. Giustina, and J.P. Bilezikian, Endocrine 71, (2021)

52. T.M. Uyeki, A.K. Mehta, R.T. Davey, A.M. Liddell, T. Wolf, P. Vetter, S. Schmiedel, T. Grünewald, M. Jacobs, J.R. Arribas, L. Evans, A.L. Hewlett, A.B. Brantsaeter, G. Ippolito, C. Rapp, A.I. M. Hoepelman, J. Gutman, N. Engl. J. Med. 374, 636 (2016)

53. L. Di Filippo, A.M. Formenti, P. Rovere-Querini, M. Carlucci, C. Conte, F. Ciceri, A. Zangrillo, A. Giustina, Endocrine 68, 475 (2020)

54. J. Liu, P. Han, J. Wu, J. Gong, D. Tian, J. Infect. Public Health 13, $1224(2020)$

55. J.L. E. Nieto-Tosses, C. Verdia-Baguena, J.M. Jmenez-Guardeno, J.A. regla-Nvaa, C. Castano-Rodriguz, R. Fernandez-Delgado, J. Torres, V.M. Aguilella, L. N, Virology 485, 330 (2015)

56. A.C. Walls, Y.J. Park, M.A. Tortorici, A. Wall, A.T. McGuire, D. Veesler, Cell 181, 281 (2020)

57. R.M. Wösten-Van Asperen, R. Lutter, P.A. Specht, G.N. Moll, J. B. Van Woensel, C.M. Van Der Loos, H.Van Goor, J. Kamilic, S. Florquin, A.P. Bos, J. Pathol. 225, 618 (2011)

58. J. Xu, J. Yang, J. Chen, Q. Luo, Q. Zhang, H. Zhang, Mol. Med. Rep. 16, 7432 (2017)

59. N. Vyas, S.J. Kurian, D. Bagchi, M.K. Manu, K. Saravu, M.K. Unnikrishnan, C. Mukhopadhyay, M. Rao, and S.S. Miraj, J. Am. Coll. Nutr. (2020)

60. H.K. Biesalski, Curr Opin, Clin. Nutr. Metab. Care 24, 18 (2021)
61. J. Rhodes, F. Dunstan, E. Laird, S. Subramanian, R.A. Kenny, BMJ Nutr. Prev. Heal. 3, 118 (2020)

62. R.K. Moozhipurath, L. Kraft, and B. Skiera, Sci. Rep. 10, (2020)

63. L. Tang, M. Liu, B. Ren, Z. Wu, X. Yu, C. Peng, and J. Tian, Sci. Total Environ. 751, (2021)

64. F.A. Giustina A, Br. Med. J. (2020)

65. H.W. Kaufman, J.K. Niles, M.H. Kroll, C. Bi, and M.F. Holick, PLoS ONE 15, (2020)

66. N. Liu, J. Sun, X. Wang, T. Zhang, M. Zhao, H. Li, Int. J. Infect. Dis. 104, 58 (2021)

67. D. Ferrari, M. Locatelli, M. Faraldi, G. Lombardi, Biology 10, 237 (2021)

68. M. Pereira, A. Dantas Damascena, L. M. Galvão Azevedo, T. de Almeida Oliveira, and J. da Mota Santana, Crit. Rev. Food Sci. Nutr. (2020)

69. R. Munshi, M.H. Hussein, E.A. Toraih, R.M. Elshazli, C. Jardak, N. Sultana, M.R. Youssef, M. Omar, A.S. Attia, M.S. Fawzy, M. Killackey, E. Kandil, J. Duchesne, J. Med. Virol. 93, 733 (2021)

70. H. Yisak, A. Ewunetei, B. Kefale, M. Mamuye, F. Teshome, B. Ambaw, G.Y. Yitbarek, Risk Manag. Healthc. Policy 14, 31 (2021)

71. S.F. Ling, E. Broad, R. Murphy, J.M. Pappachan, S. PardesiNewton, M.F. Kong, E.B. Jude, Nutrients 12, 1 (2020)

72. M.L. Brandi, A. Giustina, Trends Endocrinol. Metab. 31, 918 (2020)

73. D. De Smet, K. De Smet, P. Herroelen, S. Gryspeerdt, and G.A. Martens, Am. J. Clin. Pathol. 155, (2020)

74. M.F. Holick, L.Y. Matsuoka, J. Wortsman, Lancet 334, 1104 (1989)

75. G. Mazziotti, A.M. Formenti, R.A. Adler, J.P. Bilezikian, A. Grossman, E. Sbardella, S. Minisola, A. Giustina, Endocrine 54, 603 (2016)

76. A. Giustina, Endocrine 1 (2021)

77. P.R. R. R. Ebeling, R.A. Adler, G. Jones, U.A. Liberman, G. Mazziotti, C.F. Munns, N. Napoli, A.G. Pittas, A. Giustina, J.P. Bilezikian, Eur. J. Endocrinol. 179, R239 (2018)

78. V. Camozzi, A.C. Frigo, M. Zaninotto, F. Sanguin, M. Plebani, M. Boscaro, L. Schiavon, G. Luisetto, Osteoporos. Int. 27, 2593 (2016)

79. C. Annweiler, M. Beaudenon, J. Gautier, R. Simon, V. Dubée, J. Gonsard, E. Parot-Schinkel, A. Aidoud, G. Albaret, C. Annweiler, A. Audemard-Verger, M. Asfar, J. Barré, F. Berteau, G. Bertoletti, J.B. Beuscart, A. Bigot, S. Boucher, E. Botelho-Nevers, I. Bourdel-Marchasson, A.S. Boureau, A. Brangier, C. Brouessard, M.L. Bureau, N. Cardinaud, M. Carles, K. Castro-Lionard, T. Celarier, G. Chapelet, D. Chirio, E. Clabé, P. Codron, J. Courjon, É. Cua, M. Danet-Lamasou, A. Decorbez, M. De La Chapelle, E. Demonchy, E. Desvaux, M. D'Hautefeuille, G. Duval, B. Fougère, P. Gassie, N. Giroult, O. Guérin, R. Hankard, M. Houvet, S. Jobard, C. Lacout, A. Lafargue, C. Laubarie-Mouret, M. Le Floch, S. Le Gentil, S. Lléonart, J. Loison, R. Mahieu, F. Maillot, L. Martinez, M. Mathieu, A. Mauclere, P. Ménager, E. Michel, T.B. Nguyen, R. Ordonez, M. Otekpo, V. Pichon, F. Poitau, G. Pommier, V. Rabier, K. Risso, H. Rivière, A. Rouaud, C. RoubaudBaudron, G. Sacco, F. Scholastique, E. Seronie-Doutriaux, A. Tchalla, W. Trzepizur, and Y.M. Vandamme, Trials 21, (2020)

80. J.E. Manson, P.M. Brannon, C.J. Rosen, C.L. Taylor, N. Engl. J. Med. 375, 1817 (2016)

81. M. Puig-Domingo, M. Marazuela, A. Giustina, Endocrine 68, 2 (2020)

82. M. Marazuela, A. Giustina, M. Puig-Domingo, Rev. Endocr. Metab. Disord. 22, 145 (2021) 